\title{
Entrevista
}

\section{Maria Célia Marcondes de Moraes}

\author{
Entrevistadores: \\ Lucídio Bianchetti e Ana Maria Netto Machado \\ Data: 30 de junho de 2003
}

\section{Nota introdutória}

No ano de 2002 tivemos acolhida pelo Conselho Nacional de Desenvolvimento Científico e Tecnológico (CNPq), via edital universal, proposta para desenvolver pesquisa sobre a temática "Orientação/escrita de dissertações e teses em questão: produção científica e estratégias de orientadores e coordenadores de Programas de Pós-Graduação em Educação". A parte empírica da investigação previa entrevistas com professores, orientadores experientes e coordenadores e ex-coordenadores de programas de pós-graduação. Foi no contexto de desenvolvimento dessa pesquisa que entrevistamos a professora Maria Célia Marcondes de Moraes. Após transcrita, a entrevista foi revisada por ela, quando, à época, concedeu o aval para sua publicação.

Ainda com o impacto da sua morte, a Comissão Editorial da Revista Brasileira de Educação solicitou que disponibilizássemos a entrevista e fizéssemos uma nota introdutória. Optamos por explicitar as circunstâncias que originaram o material que segue - intento do parágrafo anterior - e fazer breves comentários sobre a entrevistada.
Falar de Maria Célia Marcondes de Moraes (1943-2008), particularmente para quem por longo e precioso tempo privou de seu coleguismo e amizade, é tarefa dolorosa, difícil. Talvez a fórmula ou a forma mais sintética seja dizer: "Ela vai fazer muita falta!". Falta como intelectual rigorosa, radical, para quem não havia espaço para concessões. Seus alunos, seus orientandos levam para suas vidas o exemplo de uma pessoa estudiosa, incentivadora, desafiadora, professora e orientadora dedicada para quem não havia empecilhos nem fronteiras quando a questão era a ilustração e a busca por transformar-se em cidadão do mundo. Ela não somente acreditava e vivia como incentivava a compreender que, como dizia Marx em um dos prefácios de $O$ capital: "Não há estrada real para a ciência, e só têm probabilidade de chegar a seus cimos luminosos aqueles que enfrentam a canseira para galgá-los por veredas abruptas". Essa é uma das suas características, que será possível depreender de muitas de suas respostas e reflexões, presentes na entrevista a seguir e nos numerosos escritos que legou.

A área de educação perde uma das suas mais proeminentes protagonistas na defesa daquilo a que 
ela sempre se referia como "a necessidade de construir o perfil epistemológico da área”. As polêmicas travadas no interior da área, quando foi sua representante na Coordenação de Aperfeiçoamento de Pessoal de Nível Superior (CAPES), originavam-se das renhidas batalhas nas quais se envolvia em disputas entre as áreas, uma vez que a educação não goza do prestígio e do reconhecimento esperados nas instâncias que avaliam e financiam a pós-graduação. Por fazer essa defesa, muitas vezes entrou em atrito com seus pares. Não há como deixar de reconhecer, porém, que sua presença nos fóruns e, principalmente, sua imediata disponibilização, pela rede, por meio de palestras, de conversas ou outras formas, de tudo que se originava da CAPES e posteriormente do CNPq garantiu a todos, indistintamente, acesso a preciosas informações que permitiram que os pesquisadores, os orientandos e todos os envolvidos com a pós-graduação tivessem conhecimento sobre muito do que, nesse campo, interferia na vida das pessoas e dos programas. $\mathrm{O}$ reconhecimento dessa generosidade foi um ponto de convergência, manifestação marcante em todas as mensagens que nós, seus colegas do Programa de Pós-Graduação em Educação da Universidade Federal de Santa Catarina (UFSC), recebemos.

Como ser humano, fica um exemplo: nem mesmo a doença foi capaz de abater seu ânimo enquanto esteve entre nós. Como diz o colega Valdemar Sguissardi, “essa disposição para a 'briga' necessária e justa fez com que também fosse, e o seja para o futuro, lembrada por sua luta contra a doença que, infelizmente, vitimou-a e no-la roubou sem piedade, muito antes do racionalmente esperado".

Sua ausência física, contudo, é compensada por alguns de seus traços mais reconhecidos - pesquisar, escrever, publicar, além de suas qualidades como editora científica - que nos deixou como preciosa herança. A título de demonstração, indico ao término da entrevista alguns de seus escritos para serem lidos, relidos, revisitados. Por essa pequena amostra podemos constatar mais uma de suas características marcantes: o trabalho e a produção intelectuais coletivos.

Por fim, diria que, de quem era rigorosamente agnóstica, surpreende a crença inabalável na ilustração, no esclarecimento, na ciência, na filosofia, na educação. Que Maria Célia seja nossa mediadora junto a Atena e Minerva.

Florianópolis, abril de 2008

Lucídio Bianchetti

Programa de Pós-Graduação em Educação Centro de Educação da Universidade Federal de Santa Catarina

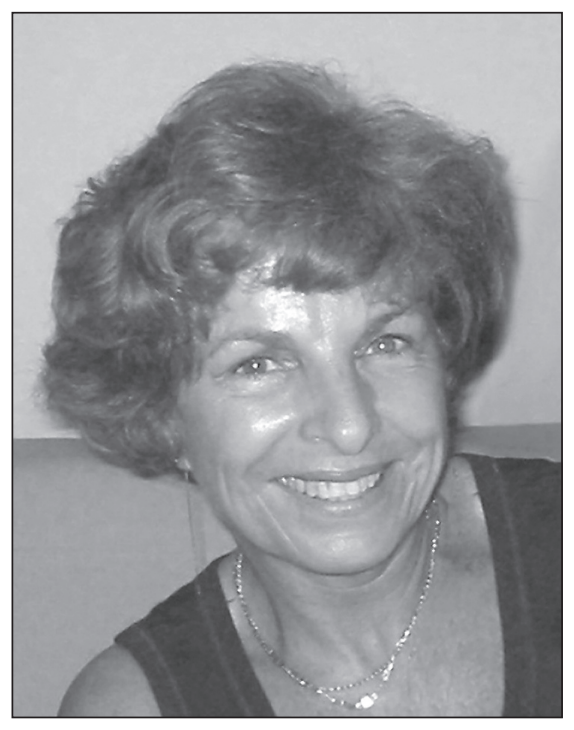


Esta entrevista reveste-se de uma condição especial porque tu ocupas e ocupaste várias funções de destaque na coordenação de processo de pesquisa e pós-graduação. Mas vamos começar a falar sobre orientação, sobre a tua experiência, os processos, como tu vivenciaste as metamorfoses que foram sofrendo a tua maneira de orientar, a tua experiência como coordenadora, coordenando colegas orientadores e a tua experiência agora como representante da área de educação na CAPES. São experiências que certamente te permitem enxergar, abrir uma série de janelas a que outras pessoas não tiveram acesso.

Começo contando uma historinha (logo eu, que não valorizo histórias de vida...) de minha vida, lembrando que essa trajetória à qual você se refere tem apenas 12 anos, uma vez que eu defendi minha tese de doutorado em 1990, em dezembro. Portanto, sequer dá para contar o ano de 1990. Então, digamos assim, trata-se de uma história condensada em um espaço muito pequeno de tempo. Esse é um aspecto importante a lembrar.

Quando defendi minha tese, eu trabalhava no Departamento de Economia da Universidade Federal Fluminense (UFF), que naquele momento acabara de abrir seu curso de mestrado. Foi lá que iniciei minha trajetória na pós-graduação, com a disciplina filosofia da ciência econômica. A rigor, vim trabalhar na pósgraduação na área de educação aqui na UFSC, em anos muito recentes, a partir de 1996. No doutorado, só a partir de 1998, quando abrimos a linha de pesquisa "Educação, história e política". Assim, minha história na pós-graduação, apesar de intensíssima, é muito curta. Talvez por isso seja tão intensa, por ser tão condensada no tempo. Não vem ao caso mencionar aqui por que fui parar em um curso de economia...

\section{Eu até já ia te perguntar, mas...}

Falar agora sobre isso, me parece, foge um pouco ao nosso objetivo. De todo modo, era uma situação altamente privilegiada. Uma vez que eu não era economista, não podia ser chefe de departamento, não podia ser representante, não podia fazer nada, a não ser dar aula, pesquisar e orientar. Uma maravilha, realmente muito bom! Além do mais, como diziam meus colegas (eles punham a mão em meus ombros e diziam): "Maria Célia faz poesia, nós fazemos ciência".

\section{Que bons tempos!}

Realmente, bons tempos em que eu fazia filosofia e poesia (1985-1995) no curso de economia. Na graduação, eu ministrava uma disciplina chamada metodologia da ciência econômica, na qual eu discutia questões de metodologia e de produção de conhecimento, que é meu forte, minha área de pesquisa de sempre. Isso com alunos de quinta fase, que já tinham lido $O$ capital, lido A riqueza das nações, de Adam Smith, de modo que meus alunos eram muito maduros em termos teóricos e aptos a discutir as questões de metodologia na economia. Foi mesmo uma situação privilegiada. Na pós-graduação (1992-1993), eu ministrava uma outra disciplina, filosofia da ciência econômica. Com essa disciplina trabalhei dois anos na pós e orientei duas dissertações de mestrado, de dois marxistas, naturalmente.

Houve então o pós-doutorado, na Inglaterra, na School of Continuing Education, da University of Nottingham, entre janeiro de 1993 e julho de 1994. Na volta, fiz concurso para professora titular na UFSC. Um ano depois, meu contrato foi assinado e vim de mudança para cá, em 1995. Dez meses após a vinda, eu me tornei coordenadora do Programa de PósGraduação em Educação de uma universidade que eu não conhecia, de um programa que eu não conhecia e de uma área que não era a minha de origem. Apesar de eu ter feito doutorado em educação (em história da educação), sou graduada e mestre em filosofia. Então, assumi um programa de uma área na qual nunca tive efetiva inserção. Minha experiência aqui na pós foi, digamos, uma entrada na área a fórceps, entendeu? Eu ficava até altas horas estudando. Receava passar qualquer informação, porque não tinha segurança, tinha que estudar para não dar uma informação errada. Como você pode ver, foi uma experiência muito 
intensa mesmo. Comecei orientando um monte de gente e dissertações acerca de tudo e qualquer coisa. Felizmente, hoje em dia essa experiência está definitivamente fora - eu acho - do horizonte dos professores da pós-graduação. Em 1996, eu orientava temas como o ensino de geografia, educação de adultos, jovens e adultos no Amazonas, Vygotsky, Lukács, história da educação, enfim, coisas que eu dominava e outras das quais eu não tinha a mais remota noção. No entanto, era assim que se orientava naquele momento, e acabaram saindo boas dissertações, acredito, muito mais por mérito dos alunos do que da orientadora. Eu só perguntava: cronologia, história, justifique o período, a escolha do tema, ou seja, as questões de método e de procedimentos. Agora, a temática, o objeto em si... Eu diria que a minha primeira experiência de orientação na área de educação foi a mais difícil. Não foi assim com os economistas, porque lá os orientandos haviam lido Marx, e Marx eu conheço razoavelmente bem para poder orientar, mesmo sem ser economista - ou pour cause. Mas aqui não. Na educação, nesse primeiro momento, foi quase uma aventura, um esforço enorme da minha parte em estudar e acompanhar temas dos quais eu não tinha idéia nem interesse, pois fugiam completamente da minha história como pesquisadora.

É que era um período também em que os alunos entravam sem orientador. Era comum o professor voltar do doutorado e receber alunos...

Ah sim, pegava-se qualquer herança.

E as linhas ainda não estavam tão definidas como hoje.

Você tem razão, as linhas não tinham definição precisa. Eu me lembro da primeira seleção para o mestrado de que eu participei aqui na UFSC e nós, membros da comissão, nos perguntávamos: esse tema será interessante para o Programa? Não se perguntava se haveria ou não orientador. Houve um rapaz, um artista, que foi admitido por esse motivo: achávamos que alguém de artes traria mais riqueza para o Pro- grama! E trouxe mesmo, só que o pobre aluno não tinha orientador, não tinha disciplina de seu interesse específico. Foi uma experiência muito penosa para todos, sobretudo para ele.

\section{A gente tinha que "dar" o objeto de pesquisa, o} tema, porque a pessoa...

Naquele momento havia uma compreensão muito frouxa, mas muito frouxa mesmo, do que fosse um programa de pós-graduação ou uma linha de pesquisa. A minha gestão (1996-1998) aqui, como coordenadora, coincide com as grandes mudanças no sistema de avaliação da CAPES e de suas repercussões na pós-graduação. De minha parte, portanto, não foi só um conhecimento do funcionamento do Programa, da área, da universidade, mas foi acompanhar a introdução de uma nova mentalidade na pós-graduação brasileira. Isso se confundiu um pouco comigo, essa pessoa nova na instituição e na área. Ou seja, eu também estava apreendendo essa mentalidade que a CAPES começava a impor. E foi muito difícil. Eu tive o privilégio de estudar com um professor de filosofia, uma pessoa maravilhosa, o José Américo Pessanha, que dizia: em filosofia tudo parece muito difícil; mas é só até obter a chave do código lingüístico. Uma vez que se tem a chave do código lingüístico, entende-se. E eu pensava comigo mesma, preciso da chave, preciso dessa chave para entender o que está acontecendo. Aos poucos eu a encontrei!

Para voltar ao eixo da sua pergunta: a fase de orientação na área começa aqui na UFSC, como lhe relatei. Ao mesmo tempo, e não obstante a variedade temática em que me envolvi, sentia um encantamento muito grande de poder trabalhar na pós-graduação com as questões que são as minhas questões: a da pesquisa, a teórico-metodológica, a contextualização histórica.

Eu me lembro de que também foi uma aventura a primeira disciplina que ministrei no mestrado, a qual intitulei Tópicos Especiais em Educação ou algo assim. Como cheguei a Florianópolis em setembro, propus ao Programa uma disciplina de dois meses. O primeiro texto foi de Derrida, Espectros de Marx. Lembro que 
os alunos me olhavam completamente atônitos, porque eles também não tinham a chave do código lingüístico do texto. E eu pensava: mas como não entendem Derrida? Mais ainda, perguntavam - aliás, esta é a pergunta que eu mais ouvi aqui -: o que isso tem a ver com a educação? No começo eu tentava explicar, mas hoje eu digo logo que não tem nada a ver. Hoje eu respondo: nada! Aliás, sempre digo que minhas disciplinas não servem para nada, só para pensar. E como pensar hoje em dia caiu em desuso, elas são de uma total inutilidade, não é uma disciplina utilitarista; portanto, é totalmente inútil. E aí essa pergunta, o que tem a ver com a educação? Eu tentava explicar, e as pessoas, claro, não viam porque não tinham o código. Mas com o tempo conseguiam a chave e destrinchavam o texto; e era aquela satisfação enorme.

\section{Aquele encantamento.}

Aquele encantamento de poder descobrir, ler o texto, entender o texto e fazer finalmente as relações com a educação, que eram elas que tinham que fazer, não eu. Porque a pergunta era uma ansiedade delas, não minha. Então, não adiantava eu responder, elas é que tinham de encontrar esse caminho. Falo delas porque nesse momento eram basicamente só mulheres as minhas alunas. Aqui na UFSC eu tive a oportunidade realmente preciosa que foi a chance de trabalhar com as minhas disciplinas, com as questões teórico-metodológicas ou com questões de história, de história da educação, que é minha temática de tese. Devo muito a este Programa por isso, pela oportunidade de poder estudar e dar aula sobre um mesmo tema. Esse é um dos privilégios que a universidade pública oferece. Não conheço universidades particulares em que exista esse tipo de oportunidade, de alto custo, de você pesquisar e dar aula daquilo que você pesquisa. Isso é um privilégio fantástico e, realmente, um prazer muito grande.

\section{Um salto de qualidade.}

Um salto de qualidade, sem dúvida. Isso foi me possibilitando, junto com essa compreensão de pós- graduação gerada pela CAPES - pois as coisas não estão separadas -, perceber a pós-graduação como um ambiente altamente especializado, sofisticado. Um ambiente de pesquisa, altamente seletivo. Porque a pós-graduação, sobretudo numa universidade como a nossa, é fortemente seletiva. Há pessoas que consideram essa uma afirmação pouco democrática. Eu sempre me surpreendo, pois a pós-graduação stricto sensu é um espaço pouquíssimo democrático. A pósgraduação é o espaço da excelência e da pesquisa, que não são atividades de massa. Pesquisa é uma atividade de poucos, por definição. Então, se democracia na pós-graduação for entendida - eu acho péssima essa compreensão de democracia, em qualquer nível como massificação, nós seríamos uma péssima pósgraduação e continuaríamos a não ter democracia (no sentido anterior). Quando discuto com colegas acerca do aumento abusivo do número da vagas, que eu questiono fortemente, e ouço o contra-argumento da necessidade da "democratização do espaço público" da "única universidade federal de Santa Catarina", eu pergunto: mas qual é o número da democracia? Dez, vinte, cinqüenta, duzentos, quinhentos... Há inúmeras restrições extremamente objetivas. Veja, por exemplo, a questão do espaço físico. Ele já é um impedimento à tal democracia e não vai permitir um número de alunos maior do que sua dimensão efetiva, das possibilidades da secretaria, do número de salas de aula, das excessivas e reais aulas dos professores na graduação e assim por diante. A meu ver, a discussão sobre a democratização da pós é terreno minado.

Mas, voltando às tendências da pós-graduação que pude observar desde que estou aqui na UFSC, percebe-se que ela ficou mais seletiva, mais excludente, muito mais sofisticada em termos de linhas de pesquisa, em termos de produção de seus docentes. Como área, temos hoje um nível de produção acadêmica de alta qualidade. Posso afirmar isso porque, como representante de área junto à CAPES, tenho uma visão mais geral. O nosso Programa tem hoje produção respeitável, embora ainda mal distribuída no conjunto do corpo docente, tem inserção na área. Não tenho dúvida de que é um dos melhores programas de 
pós-graduação do país. Não temos, porém, inserção internacional e não temos condição de ter, em curto prazo, em decorrência da necessidade de domínio de línguas estrangeiras. Boa parte de nossos docentes não fala qualquer língua estrangeira e isso impede a inserção internacional, nas apresentações de trabalhos em eventos, contatos em universidades de outros países, publicações em veículos estrangeiros, convênios internacionais etc.

E teve também aquela leva de aposentadorias de professores que tinham esse domínio...

Creio que sim. Em contrapartida, no passado bem recente isso não estava em questão para os programas, eram sempre iniciativas individuais. Agora é que as agências têm convênios internacionais e os incentivam. Há que se considerar, também, que hoje há congressos em tudo que é canto no mundo, e então as possibilidades de intercâmbio aumentaram muitíssimo nos últimos anos. Claro, para isso você tem que ter domínio de língua estrangeira, e não é o nosso caso. Obviamente, isso não impede que sejamos um Programa de importante inserção nacional e de altíssima qualidade. Aliás, não é preciso ser um Programa de inserção internacional para ser bom. Para mim, já é excelente que sejamos um grande programa 5, que é a excelência nacional. Eu acho pretensão almejar o conceito 6; ao contrário, temos que ser um excelente programa 5, de ponta. Essa longa preleção foi apenas para dizer que hoje tenho condições, em uma universidade pública que tem um programa com conceito 5 , de orientar quem está absolutamente dentro da minha linha de pesquisa.

\section{Isso foi uma conquista do Programa.}

Sim, é uma conquista do Programa. Em minha linha de pesquisa, "Educação, história e política", quando há reunião para discutir o processo de seleção, define-se o total de vagas que a linha vai abrir, quantas vagas cada um de nós vai abrir, sempre com a condição de que o número de vagas está condicionado ao interesse do orientador, à existência de candidatos com projetos afinados com os projetos de pesquisa de cada um. Assim, se não houver candidato com projeto adequado à minha temática, eu não abro vaga. Como você vê, é uma situação muito diferente de quando eu entrei aqui, quando se abriam vagas não importando o candidato ou o tema. Podia estar pesquisando o sexo dos anjos; se passasse na seleção entrava e tinha que ter um orientador. Agora é o contrário, a linha define vagas, define seu interesse. Portanto, o programa assume o perfil de programa e não de curso.

\section{E alcança nível de excelência.}

E da excelência. Se for um programa, então, tem perfil, tem interesses, tem uma cara. Assim, por exemplo, no caso do nosso programa, não adianta você querer pesquisar no campo das artes. Infelizmente, não temos ninguém para orientar nesse campo. $\mathrm{O}$ candidato deve ir a outro lugar, pois este Programa aqui não tem essa cara.

Maria Célia, e esse salto, que foi tão rápido, porque essa trajetória tu acompanhaste, foi tão rápido. Enfim, é uma questão estratégica para os programas que ainda estão numa fase um pouco anterior, como você viveu. Enfim, o que impulsiona exatamente, quais fatores fizeram com que isso se desse tão rápido? Essa estruturação em linhas, essa possibilidade de captar apenas...

Eu acho que aí entra a "cultura" CAPES.

Tu achas que a responsabilidade é da...

Ah, a "cultura" CAPES, foi...

Acho que há uma palavra que é chave: indução.

Creio que sim, a CAPES induziu. Veja, hoje o conceito de programa - e não mais de cursos a serem avaliados - define a possibilidade (ou não) de acesso de seus docentes a certos privilégios, como propor 
um convênio internacional. Pessoalmente, acho isso de uma perversidade... Para ficarmos com o exemplo: para propor um convênio internacional, o programa tem de ter no mínimo nota 5. Ocorre que quem faz a proposta e que se responsabiliza por ela sou eu ou outro docente. Há inúmeros programas com nota 4 que têm em seu corpo docente professores com qualificação suficiente e necessária para se responsabilizar por um convênio, mas o conceito do programa impede. Então, a classificação deixou de ser uma classificação que dizia respeito ao programa e passou a atingir e a limitar a atuação do corpo docente.

\section{Comprometeu de algum modo?}

Comprometeu, sim. Hoje se tem uma cultura muito fortemente, digamos assim, de cobrança. Cobra-se dos docentes: publicou? Não publicou? Tem trabalho aprovado na Associação Nacional de Pós-Graduação e Pesquisa em Educação (ANPEd)? Agora mesmo fiquei sabendo que três de meus orientandos tiveram trabalhos aceitos na ANPEd. Sabe a primeira coisa que eu fiz? Ligar para o coordenador do Programa! Olha que maluquice... Porque todos só pensam no relatório anual, que contabiliza a produção do programa e que vai ser avaliado pela CAPES. Então, se nossa produção acadêmica é ótima para enriquecer o Lattes, não se pode esquecer que ela também tem impacto na avaliação do programa. Então, foi essa cultura... Agora, eu brinco muito que foi uma aculturação a fórceps. Nós tivemos que aprender a orientar em dois anos as dissertações de mestrado, sem perder a qualidade - porque isso foi um ponto de honra -, e aprendemos.

\section{É sobre isso depois...}

Então depois a gente volta, não vou falar sobre isso agora, mas insisto nessa aculturação. O tempo ficou rígido, não só a compressão do tempo para a dissertação, mas o tempo da formação, que se perdeu. Agora, os alunos que entram no mestrado, em sua maioria, já têm experiência de pesquisa. Na minha linha de pesquisa, em sua esmagadora maioria, só en- tram candidatos com experiência de pesquisa anterior, ou seja, só entram os "PIBICs" [Programa Institucional de Bolsas de Iniciação Científica], ou seja, aqueles que participaram do Programa Institucional de Bolsas de Iniciação Científica. Isso significa uma importante mudança na cara da pós-graduação.

A cultura foi e está sendo assumida pelos orientadores.

Pelos orientadores.

Porque os alunos sempre vão reclamar, sempre vão... Sempre têm razões, mas os orientadores assumiram.

Assumiram, sem dúvida alguma. Há um aspecto interessante. Quando eu entrei aqui, eram raros os alunos da pedagogia que entravam na pós-graduação. A meu ver, havia um abismo entre a pedagogia e a educação. Foi com o PIBIC que começamos a formar pesquisadores nesse nível. Aliás, é essa a idéia do PIBIC: começar a formar pesquisadores na graduação.

\section{E desde quando isso começou?}

O PIBIC é recente. Aqui na UFSC é bem recente.

E havia também o Plano Institucional de Capacitação Docente (PICD), com muitos professores de universidades federais buscando qualificação...

Tinha, tinha. Havia aquele grupo grande de professores do Amazonas...

Então esse grupo foi-se qualificando nas universidades que tinham mestrado e doutorado. Como não houve mais concurso nas federais, essa clientela foi diminuindo. Mas, ao mesmo tempo, melhoraram os egressos dos cursos de pedagogia, ciências sociais. Nós temos muitos alunos de sociologia...

Temos mesmo. Mas eu queria voltar à questão da pedagogia. Eu me lembro de discutir muito nas 
reuniões da pedagogia. Eu dizia: Gente, não é possível, não é possível... Quem nós estamos formando?. Será possível que não estamos formando ninguém que aspire à pós-graduação? Ou que não seja capaz de passar na seleção? Para mim era um conflito dar aula num curso em que os alunos não tinham chance de ir para o melhor lugar da universidade, a meu ver, a pós-graduação. Achava então e continuo pensando assim, a pós é a melhor inserção que se pode ter na universidade, pois é onde você encontra interlocutores. Mas essa relação entre a pedagogia e a pós-graduação mudou, esse quadro mudou inteiramente, inteiramente. Nós hoje temos um número significativo de alunos da pedagogia; de outros cursos também, mas muitos da pedagogia. Mas os que entram, com poucas exceções, são alunos com formação em pesquisa. O que acontece, então? Esses alunos entram no mestrado, se matriculam nas disciplinas chamadas Seminário de Dissertação de suas respectivas linhas de pesquisa, o anteprojeto já vem pronto, pois foi feito nas atividades de pesquisa da graduação. Os mestrandos passam um ano na "linha de montagem" burilando o anteprojeto, chegam ao fim do primeiro ano da pós com o projeto pronto, dali a pouquinho qualificam e sobra um ano para a defesa. Esse processo resultou em que os dois anos não tenham implicado a desqualificação dos conteúdos das dissertações, porque nós elevamos o patamar de exigência na entrada. Assim, ninguém mais entra no mestrado na estaca zero. Isso acabou.

\section{Então não são só dois anos que interferiram.}

Não são dois anos, na verdade continuam quatro anos. Os mesmos quatro anos que existiam, só que os dois primeiros começam na graduação.

Isso é um dado importante que a pesquisa está mostrando: a iniciação científica e o trabalho em grupo, o trabalho em grupos de pesquisa...

Isso realmente mudou, mudou a cara da pósgraduação, sem dúvida alguma. Hoje as minhas pes- quisadoras de iniciação científica (IC) da graduação, as meninas, discutem questões conceituais de peso impensáveis poucos anos atrás. Quer dizer, elas vão chegar ao mestrado com um patamar teórico de alto padrão. Já apresentam papers em congresso, por exemplo. Este ano já é o segundo em que vão apresentar, pois foram aceitas no Congresso da Sociedade Brasileira de Sociologia, em Campinas. Então realmente se trata de uma outra concepção de aluno de mestrado. $\mathrm{O}$ que eu considero ainda bastante complicado é que nós temos um número muito alto de alunos. Se tomarmos como referência a relação aluno-professor, nem é tão alto assim, mas considerando-se as exigências de pesquisa de um curso de mestrado, o número excessivo acaba sendo prejudicial. Não por acaso o CNPq vem diminuindo o número de bolsas no mestrado, que se tornou, digamos assim, uma transição para o doutorado, que é onde se efetiva ou ainda se consegue ter um bom padrão de pesquisa.

\section{Então o mestrado seria uma preparação?}

É, uma preparação; eu diria que se transformou nisso. Então, só para fechar a questão da orientação: desde que cheguei à UFSC, passei da fase da aventura para a fase da hiperespecialização. Hoje só aceito orientar quem está absolutamente afinado com minha pesquisa, quem vem compor meus estudos. Considero impossível uma pesquisa séria, consistente, atirando em todas as direções. A meu ver, a orientação está vinculada aos estudos do orientador. É isso que faz com que um programa de pós-graduação realmente se qualifique, quando essa cultura passa a ser disseminada por todo o corpo docente. UFSC?

\section{E efetivamente tu enxergas isso no programa da}

Não, de forma alguma. Talvez em algumas das linhas isso já tenha ocorrido, mas não no conjunto. Até porque ainda é muito forte o espírito democratista: essa é uma universidade pública, única universidade federal do estado de Santa Catarina... Penso que há ainda dentro 
do Programa um conflito entre pessoas que têm uma concepção de excelência que, infelizmente, é considerada elitista, pouco democrática etc. etc. Como é a minha, por exemplo. Por exemplo, não aceito aluno especial em minhas turmas. Ou raramente, quando os aceito, são aqueles que conheço e que pesquisam em meu campo de interesse. Eu não estou aqui para brincar, mas para pesquisar e ensinar coisa séria. Estudo muitíssimo para dar aula e, portanto, não faço nivelamento. Essa é, para mim, a concepção de pós-graduação. Ela é considerada elitista por muitas pessoas, e certamente minha percepção de pós não é hegemônica.

Voltando àquela questão: quando tu dizes: "Bom, apreendemos a orientar em dois anos, sem prejuizos para a qualidade”, tu falaste que não são só dois anos, porque existe a iniciação e ela deixa os alunos mais preparados. Mas, de qualquer maneira, assim, digamos, a miudeza dos processos de orientação teve que ser um pouco incrementada. Quer dizer, algumas estratégias novas. É sobre isso que gostaria que falasses, sobre as dificuldades enfrentadas nesse processo. Quais foram os ganhos e as perdas?

Penso que a grande perda com a introdução dos dois anos de prazo para a defesa, os 24 meses, não foi da qualidade da dissertação, mas da formação. Nós perdemos o tempo, perdemos o tempo, não perdemos tempo. Nós perdemos o tempo que tínhamos para um maior número de disciplinas de formação. Isso é que eu acho que mais faz falta. Os mestrandos tinham mais tempo para cursar disciplinas, para conhecer mais coisas, para ter mais acesso ao convívio da pós, para ter uma convivência com o ambiente da pós-graduação mais intenso. Mesmo mantendo-se os quatro anos, dois deles são na graduação, o que é muito diferente de tê-los todos na pós-graduação. Acho que essa é a maior perda.

Isso significa que houve perda no que se pode definir como o necessário tempo de maturidade?

Tempo de maturidade. Nós até chamávamos de "tempo do namoro", no qual os alunos entravam sem orientador, tinham um tempo para conhecer os professores e vice-versa, e só depois é que se escolhia. Foi esse o tempo que se perdeu: o da curiosidade dos alunos em cursar disciplinas, o que nós incentivávamos muito. Eu acho que essa foi a grande perda. Do ponto de vista da orientação, a mudança foi tão rápida que tivemos que nos adaptar sem demora à nova situação. Em primeiro lugar, a mudança do perfil dos que entram, como disse. Agora são alunos que já têm o hábito da pesquisa, têm acesso aos mecanismos básicos de um pesquisador, uma pesquisadora, que já cursam as disciplinas de pesquisa dentro da linha de pesquisa em que entraram no mestrado e passam um ano discutindo, por exemplo, em nosso caso, questões metodológicas de história e política. Quero dizer com isso que se criou um aparato de formação no mestrado que, a rigor, transcende o problema da orientação, percebe? Então, orientar nessa ambiência facilita muito. Isso não tínhamos antes. Apesar das muitas reclamações, assumir a "nova cultura", como você diz Lucídio, não foi uma coisa tão violenta. Quer me parecer que a organização dos cursos de forma que se crie essa estrutura voltada para a dissertação fez com que o processo tivesse sido menos violento para os orientadores. As dissertações, claro, ficaram mais enxutas. Eu sempre digo que a minha tese de doutorado é o exemplo do que não deve ser uma tese. Minha pesquisa foi sobre Francisco Campos, que foi o ministro da Educação do Getúlio Vargas nos anos de 1930. Bom, para chegar a Francisco Campos nos anos de 1930, eu comecei estudando o ciclo do café! A tese tem cinco capítulos e só o último trata da tese propriamente dita. Isso tudo demandou um tempo de estudo enorme, foi muito interessante, mas isso acabou. Uma tese como essa é impensável hoje em dia e muito menos uma dissertação, por exemplo, que tenha como objeto a UFSC e comece a falar da história de Santa Catarina, da imigração dos açorianos etc. etc. Hoje os objetos se delimitaram.

\section{Esse é um ponto importante.}

É claro que a contextualização histórica, pelo menos em nossa linha de pesquisa, continua sendo 
fundamental, mas ela é também uma contextualização pontual, já não é aquela grande história do modo de produção capitalista para se chegar até os dias de hoje. Isso realmente acabou. A mudança no perfil da dissertação ou da tese, volto a dizer, não significa sua desqualificação, não significa perda de qualidade. Embora eu não tenha feito essa pesquisa e falo a partir de uma observação pouco profunda, acho improvável que as dissertações que levavam quatro ou cinco anos para serem concluídas são melhores ou mais consistentes do que as que são feitas hoje, em menos tempo.

Sabes do que eu me lembrei? Na França se falava de estudos doutorais. Uma coisa é a tese, outra coisa são os estudos doutorais. Os estudos acabam minimizados, a tese não. As dissertações estão acontecendo, são mesmo pesquisas?

São pesquisas e bem pontuais, delimitadas, o que eu não considero ruim, porque acho que a delimitação de um objeto é também um aprendizado. Eu diria a vocês que um problema da área de educação é definir objetos com precisão. Tal dificuldade é mais comum do que pode parecer. Assim, a nova condição dos cursos de pós nos obrigou a uma definição mais precisa do objeto da dissertação ou da tese, e penso que está sendo muito benéfico, muito pedagógico para a área. A área de educação é um pouco missionária, salvacionista, e às vezes quer abraçar o mundo com as mãos. A nova cultura, de algum modo, tem-nos obrigado a precisar melhor nossos objetivos e nossos procedimentos de pesquisa. Isso pode parecer uma tolice, mas não é. Um problema sério da área de educação é a definição de seu perfil epistemológico. Por ser a educação uma prática social, ela tem um número de interfaces imenso. Basta ver o número de periódicos em que a área publica. Nós estamos concluindo a Qualis da CAPES. Entre os melhores periódicos em que a área publica, por exemplo, os classificados como Internacional A, estão numerosos periódicos de outras áreas, algumas bem distantes da educação. Se, por um lado, isso é muito bom, é também muito complicado particularmente em termos de perfil da área, o que é fundamental para sua afirmação na comunidade científica. Então nós temos que cuidar disso, o que não é uma tarefa simples, porque vai contra a própria cultura da área, que alimenta suas múltiplas e variadas interfaces.

\section{Tu vislumbras alguma saída para essa questão?}

Se há uma coisa que eu tenho feito como representante de área é brigar para conseguimos fechar um pouco mais esse perfil. Essa questão interfere em cada um dos aspectos de que nós estamos falando, interfere na pósgraduação. Hoje, por exemplo, quem vai publicar deve publicar preferencialmente em periódico classificado. Se você pertence a um programa, não dá mais para sair publicando no periódico de que você gosta, que você conhece etc. Se o periódico não for bem classificado, há prejuízo para seu curriculum vitae individual e para o programa. Interfere nas solicitações de bolsas e auxílios, pois o que se julga e se leva em conta fundamentalmente é a produção científica. Interfere, ademais, na classificação do programa pela CAPES.

\section{É o refinamento dos critérios.}

É o refinamento dos critérios. Para nós, um refinamento cruel, dado o perfil de uma área que demanda publicações em revistas, jornais, periódicos locais, que são as leituras preferenciais dos professores da rede.

Esse tema requer uma formação para os programas?

Eu tenho recebido muitos e-mails de coordenadores. Outro dia eu recebi de um coordenador de curso novo, curso novinho, foi aprovado agora na última avaliação. A direção da universidade, que é uma universidade do interior de São Paulo, particular, pediu à coordenadora do curso que me mandasse um e-mail perguntando em que periódicos eles deveriam publicar.

\section{O pragmatismo levado ao extremo?}

Aí eu falei, meu Deus, isso é uma loucura, porque já... Percebe? O reitor já quer saber em que periódicos 
os professores devem publicar - trata-se de universidade particular - e vai obrigar aqueles professores a publicar na Qualis, entendeu?

\section{Mas é difícil conseguir isso.}

Não, consegue sim, porque a Qualis não é só excelência, mas tem local A, B e C, certo?

\section{A questão é estar no sistema.}

Tem de estar no sistema. O problema... Porque a Qualis... O que é a Qualis? Qualis é onde a área publicou. Se alguém publicou, docente ou discente, a área tem de classificar usando todos os meios ao seu alcance. Claro que não qualificamos qualquer coisa, o que nem sei o que é, não sei se é um jornal qualquer que se apresenta como periódico... Então, classifica-se aquilo que se consegue classificar porque se encontra algum parâmetro, como por exemplo o de ter sido classificado por outra área e tal... Para você ter uma idéia: nós tínhamos 1.500 títulos. Nós classificamos 340. Claro que, nesses 1.500, há títulos repetidos, há anais, há revistas tipo Veja.

Então, voltando à sua pergunta sobre orientação, quer dizer, eu acho importante pontuar esses dois aspectos: o que nós perdemos foi a formação, o que ganhamos foi uma formação mais precisa de pesquisadores e um treinamento, eu diria, porque na verdade é isso, um treinamento para delimitação de objeto, de justificativa, que as pessoas aprendem a fazer.

Isso não teria mesmo, digamos... Um grau de mais técnica?

Em alguns casos, eu acredito que sim. É uma dimensão técnica, e chama-se técnica de pesquisa, sempre se chamou assim. Eu não tenho preconceito contra a técnica de pesquisa. Se a técnica é associada a um aprofundamento teórico-metodológico, a técnica é ótima; ela é ruim quando ela é um objetivo em si mesmo... Nesse caso, não há pesquisa que resista.

Mudando um pouco o rumo da conversa: como te posicionas sobre a questão da orientação individual ante a orientação grupal, inclusive com a presença de vários orientadores? Hoje em dia, muita gente está trabalhando em grupo, até pela quantidade de orientandos. Não sei se seria essa exatamente a razão que levou à intensificação orientação grupal. Como vês isso?

$\mathrm{Eu}$ pessoalmente não faria orientação grupal. Tenho muita dificuldade de trabalhar com outros orientadores, talvez pelo tipo de pesquisa que faço, que é de aprofundamento teórico. Teria dificuldades de trabalhar; não sei bem como funciona. Eu sei que algumas pessoas fazem, mas eu pessoalmente não tenho o hábito de trabalhar em conjunto no processo de orientação.

\section{Com grupos de orientandos?}

Ah, não, com grupo de orientandos, sim; mas com outros orientadores, não. Com os meus orientandos, sem dúvida, temos intensos e extensos encontros. Esse fim de semana mesmo, foram 48 horas trabalhando, porque hoje é o último dia de entrega para a CAPES da proposta de doutorado sanduíche de dois de meus orientandos. Então o fim de semana foi em cima do projeto dos dois, foi direto. Então eu não tenho hora; são verdadeiros encontros... A gente tem encontros sistemáticos também de aprofundamento, de discussões, que normalmente são aulas do doutorado também. Agora eu estou um pouco afastada, mas normalmente associo as aulas do doutorado com as pesquisas dos meus orientandos, o que dá um resultado muito bom.

E que lugar, que espaço ocupa a escrita nesse processo de conhecimento?

A nossa prova... É um dos poucos cursos que tem prova escrita para o doutorado. Para o mestrado é mais comum, mas nós temos prova escrita para o doutorado e não abrimos mão dela, porque não se faz a prova para aferir conhecimento, mas para saber se as pessoas sabem escrever. Porque se não souber escrever não 
sai dissertação em dois anos, não sai tese em quatro anos nem sai em ano nenhum. Porque a importância da escrita ou do saber escrever é fundamental. $\mathrm{Na}$ verdade, fui co-autora de teses, de dissertações: a rigor eu reescrevi algumas dissertações. Isso eu jamais faria novamente, em hipótese alguma. Mas orientador de mestrado, via de regra, é co-autor. Você definitivamente não pode propor - num curso de pós-graduação que demanda professores altamente qualificados, cursos especializadíssimos, linhas de pesquisas etc. - e aceitar um aluno que não sabe escrever. Isso é um luxo a que este Programa não pode mais se dar. Então, há que se ter um rigor bastante grande em relação ao saber escrever, para que a escrita possa fluir com alguma regularidade, alguma lógica e coerência, para que não necessite um orientador co-autor.

Com a iniciação científica e a prova escrita para selecionar pós-graduandos, algumas dificuldades foram evitadas. Mesmo assim, outras dificuldades ainda se mantêm... Tu poderias mapear que tipo de dificuldade?

Ah, de todo tipo. Afetivas....

\section{Relações humanas?}

Relações humanas, quer dizer, tudo aparece numa orientação. Transferências, psicanaliticamente falando. O que aparece de transferências é uma loucura. Mais ainda, uma expectativa do orientando em relação ao orientador para que ele seja pai, mãe, tio, primo, tudo. O orientador, coitado, não dá conta. Quando consegue ser orientador já está fazendo muito, quanto mais suprir essa expectativa que os orientandos criam em relação a ele. Em contrapartida, como orientador você também cria uma expectativa... Você cria uma expectativa de sucesso, de excelência em relação ao seu orientando de que, pobrezinho, nem sempre ele é capaz de dar conta. Então, é um jogo assim de muita expectativa e frustração de ambas as partes. Raras vezes, quer me parecer, isso chega a explodir num problema. Normalmente as pessoas dão conta, com bom senso, dessas pequenas crises que aparecem e, aí sim, com a ajuda de colegas.

A própria entrada no mestrado e no doutorado vai colocar em teste a capacidade de equilíbrio de pessoa. É um teste, então às vezes há pessoas que não conseguem dar conta, e aí vem a frustração da aposta que vocêfez e de um retorno que...

Retorno que não vem. A seleção é muito ardilosa. Uma vez superada a prova, já nos defrontamos com o projeto e, se você se encanta com o tema do projeto, sua tendência é, digamos assim, minimizar os problemas para orientar aquela boa proposta. Só que não se elimina o problema e, de repente, o autor do projeto é um problemão e aí você tem de lidar com isso. Se esse fato é um dado de realidade, se existe nas seleções, mesmo assim eu não o considero um problema maior ou um problema insolúvel.

\section{Além de entusiasta, és extremamente otimista!}

Sou, sou sim! Eu tenho convicção de que a pósgraduação é um lugar altamente privilegiado que temos de valorizar muitíssimo. Temos que lutar muito pela pós-graduação, porque é o lugar que nos sobrou no espaço público deste país, o lugar onde se tem condições de produzir conhecimento. E isso é alguma coisa que temos de preservar com um carinho enorme, porque não podemos deixar que se perca.

\section{Custou muito para fazer e é fácil de...}

É fácil destruir. É muito fácil destruir. Mas sou otimista, talvez porque eu valorize tanto a produção do conhecimento, porque gosto de estudar, porque sei que essa é a minha praia, é o que eu gosto de fazer e sei que esse é o meu lugar. Então também tenho muita esperança de que as pessoas possam perceber isso. $\mathrm{E}$ as pessoas percebem. Estou convencida disso vendo a história dos programas de pós-graduação. Os programas deram um salto. A cultura CAPES teve seu lado perverso, mas também teve um lado pedagógico. 
Programas que até pouco tempo atrás eram bastante precários deram saltos, estão investindo. Vêem-se investimentos fortes nos programas, nos professores, na formação dos professores... No caso das instituições públicas, eu sempre digo, não podemos deixar cair, seria um crime inominável, inominável. Na defesa do espaço público, e da pós-graduação pública, em particular, não se pode perder.

Aprofundando questões relacionadas à orientação: que estratégias utilizas para ajudar os teus orientandos a desenvolver o trabalho deles?

Como eu trabalho particularmente com a teoria, meus orientandos também trabalham com teoria. E trabalhar com teoria significa definir o lugar de onde se fala... Gosto muito de um historiador inglês chamado E. p. Thompson e de uma de suas frases encantadoras: "A teoria tem conseqüências". E tem mesmo, conseqüências positivas e negativas, mas sempre tem conseqüências. Então, o lugar da teoria não é qualquer lugar. O primeiro movimento de meus orientandos é procurar definir isso. Se há um consenso de que nós todos falamos de um determinado lugar teórico, então se trata de aprofundá-lo teoricamente. Essa é a primeira tarefa, uma tarefa que demanda uma série de leituras. Todos os meus orientandos começam com uma série de leituras visando essa definição. Depois, claro, cada um tem seu objeto de análise. Um de meus alunos está saindo para doutorado sanduíche agora. Ele trabalha com cinema, cinema como forma estética, educação dos sentidos. Então, se vai estudar cinema e educação dos sentidos, é preciso antes perguntar: vai estudar como? A partir de onde? De que patamar olhar o cinema? Como espectador? Como técnico? Como análise de discurso cinematográfico? Não, isso não dá tese. Vamos, primeiro, definir: qual o recorte histórico? Como ele se justifica? Por que o cinema? Por que privilegiar um determinado diretor? O que é educação dos sentidos? O que é o cinema? E assim por diante. Todas essas questões vão circunscrevendo tanto o lugar da onde se fala como o papel que esse objeto tem em relação a esse espaço-tempo. Há um primeiro momento, que é esse do lugar, mas esse é um lugar que a gente nunca deixa, está sempre presente, sempre sendo discutido, sempre sendo aprofundado; estamos sempre lendo, sempre escrevendo sobre isso. Leio, releio trabalhos insanamente. Corrijo, exijo demais o refinamento da língua portuguesa. Os meus doutorandos escrevem bem, aprendem a escrever muito bem, aprendem a usar o Aurélio - todos eles têm o Aurélio no computador. Eu procuro corrigir os vícios de linguagem, que todos temos, pois considero isso parte da orientação. Além disso, claro, ensino a tomar bons vinhos, a comer boas comidas, a apreciar obras de arte, a ouvir uma boa música...

\section{Aquilo que se chama refinamento.}

Refinamento, porque é isso mesmo, um doutorando tem que saber olhar o mundo, ser contemporâneo do seu tempo, não é verdade? E ser contemporâneo do seu tempo é saber o que está acontecendo: quais são os melhores pratos, quais são os melhores vinhos...

\section{Essa parte é uma maravilha.}

Você gostou dessa parte? Não publica isso não, hein... Isso é segredo. Mas sábado passado, por exemplo, nós estávamos lá em casa obsessivamente vendo os projetos do Robson e da Sandra, os dois doutorandos que estão propondo projetos para doutorado sanduíche, e à noite fizemos um carpaccio, com um belo vinho, tal e tal. Então isso faz parte também.

\section{As boas combinações de uva com queijo...}

Não é? Uvas com queijo - determinados queijos -, é bom aprender a apreciar bons queijos... É sempre uma construção bem-humorada, sabe. Eu acho que faz parte da orientação poder lidar com o processo com prazer.

\section{Não dá para perder isso.}

Isso não dá para perder mesmo. É lidar com prazer com a produção do conhecimento, um entendimento 
que, gosto de pensar, esse grupo com quem eu trabalho tem. Das coisas mais propriamente humanas é o prazer pelo conhecimento, e eu acho que é uma coisa prazerosa mesmo. O processo de trabalhar um texto e poder refiná-lo, perceber, por exemplo, que mudar a ordem das idéias na exposição pode modificar toda a proposta! Esse é um processo que não tem preço; para mim, é a coisa melhor que tem na universidade.

Mudando um pouco o foco: tu poderias falar um pouco de como passaste de orientanda para orientadora? Tem muita gente saudosista: Ah! Era um tempo assim...

Eu não sou saudosista, não. Com todo respeito aos meus orientadores, tenho convicção de que sou muito melhor orientadora do que jamais fui orientada na minha vida. Eu sempre digo: eu morro de inveja, modéstia à parte, eu queria ter um orientador como eu sou. Adoro meus orientadores, meus queridíssimos orientadores de mestrado e doutorado. Mas, talvez até pela época, tive mais supervisão do que orientação.

\section{E o que é que isso tem a ver com a autonomia?}

Pois é, eu tinha toda autonomia, toda, absoluta autonomia. Há uma questão complicada quando você muda de área, como eu fiz. Na verdade, a pesquisa coloca questões que o orientador da área para a qual você se transferiu não tem necessariamente condições de responder. Esse é um problema de quem se transferiu de área e não do orientador. Por exemplo, toda a parte teórico-metodológica - e esse é o primeiro capítulo da tese - é absolutamente filosófica, e quem não tem formação em filosofia tem dificuldade de entender o jargão. Claro que minha orientadora tinha e tem a competência específica em história da educação, que ela domina na palma da mão. Nesse aspecto, ela foi inestimável. Mas, em outros pontos, eu tive que ir à luta.

\section{E no que diz respeito à indicação de fontes?}

No que se refere à indicação de fontes, que é o forte dela, foi fantástico. A culpa foi minha, que fiz uma tese aberta para a economia, para a política, para a filosofia... Ela não tinha nenhuma obrigação de dominar essas áreas, mas, de qualquer maneira, eu senti falta disso. No mestrado, que foi em filosofia mesmo, o orientador era um filósofo, ele tinha pouco tempo. Também aí foi meio tentativa e erro, sabe. Fui organizando-me e, enfim, fazendo o trabalho com pouca segurança. Escrevi a dissertação sobre um filósofo muito difícil, Heidegger, e eu não lia alemão, não sei alemão. E tinha aquele preconceito que se expressava assim: só se faz filosofia em grego ou alemão. Tenho a impressão de que dei um passo maior que a perna, embora tenha-me utilizado das traduções em inglês, francês e espanhol, e acho que, ao fim e ao cabo, saiu um pequeno texto, razoável, de introdução ao pensamento do autor. Mas, essa experiência eu não recomendo a ninguém.

\section{E o orientador te deixou fazer isso?}

Meu orientador me deu total autonomia e, embora falasse e lesse alemão, não foi capaz de me dar segurança. Por isso é que lhe digo, sem falsa modéstia, sou melhor orientadora.

Bom, e como é que se fazem Marias Célias? Como uma orientadora se constrói? Como é que tu enxergas essa possibilidade de algumas iniciativas que possam facilitar a vida dos orientadores, a partir das experiências que cada um teve como orientado. De modo geral, as entrevistas que nós temos feito evidenciam que a maioria foi simplesmente supervisionada...

Mas eu acho que era uma outra cultura também. Eu acho que naquele momento a própria concepção de pós era outra coisa. Eu fico pensando se, de repente, eu fosse fazer a minha pesquisa só no contexto do capítulo quinto da tese. Muito provavelmente minha orientadora tivesse sido perfeita. Se fiz uma tese com múltiplas interfaces, não foi culpa dela. Mas o que é que faz o bom orientador? Em primeiro lugar, o orientador tem de ser pesquisador. É impossível, impossível, na minha cabeça, um orientador que não 
seja um pesquisador e um pesquisador sério. Com produção, com apresentação de trabalhos, quer dizer, um pesquisador produtivo. Não é essa pesquisa que se faz para uso doméstico não, eu estou falando de um pesquisador que se expõe publicamente, que se expõe aos seus pares, que se está submetendo a comitês científicos de eventos, de periódicos etc. etc. É dessa figura de pesquisador que eu estou falando. Portanto, é um pesquisador que está exposto à comunidade científica. O que isso significa? Significa que é uma pessoa que está por dentro da sua temática. Eu acho que essa é uma condição de um bom orientador. Se ele faz isso é porque tem paixão por aquilo que faz, o que acho básico. Se você faz pesquisa e orienta dentro da sua linha de pesquisa, supostamente você está fazendo aquilo de que você gosta, porque eu não imagino nenhum masoquista pesquisando um tema que lhe seja desagradável. Há essa coisa boa de trabalhar com uma temática que é a sua temática e que se tem prazer em transmitir. Outro aspecto que acho importantíssimo é ter poucos orientandos. Não posso imaginar você ter dez orientandos e fazer esse trabalho de acompanhamento que eu faço. Isso só é possível porque normalmente eu oriento quatro ou cinco doutorandos e, no máximo, um mestrando. Sobre a autonomia... A autonomia, eu diria, é relativa. Como disse, para estar trabalhando comigo tem de estar trabalhando no meu circuito; se quiser fazer outra coisa, passar bem, mas comigo não dá, porque eu não sei orientar. Se for por um campo que eu não domino, quer dizer, se quiser estudar o ciclo do café, por exemplo, eu não vou deixar... Eu não vou saber orientar isso.

Mas a minha pergunta é na seguinte direção: como, tendo havido essa mudança, se passa de um orientador que supervisiona para um orientador que orienta? O objetivo é que o orientando se torne autônomo não na busca do assunto que ele quer, mas na formação de sua competência.

Ah sim, ah sim, da competência! Esse é um processo de estudo. Tem que estudar muito, mas tem que estudar muito mesmo, porque é o estudo que dá autonomia. É o salto. Como eu sempre digo: quando você começa estudar você está rente ao texto.

\section{Aderente.}

Aderente ao texto, você não descola. Mas, no processo, há um momento, que você não explica, em que, de repente, você salta, você dá um pulo, compreende, se descola e se torna autônomo. Esse é um processo do aluno, não tem nada a ver comigo.

Mas para isso o orientador tem de ter autoridade...

É autoridade e autonomia mesmo, porque na hora em que o aluno dá esse salto, ele passa a ter autonomia, porque o seu horizonte se abre. Aí vem o papel do orientador: abriu esse horizonte, ok, tem essa perspectiva, então para onde vamos? Começa então uma discussão em um outro patamar, a descoberta do caminho mais adequado, mais coerente... E, claro, também às vezes, a descoberta do caminho mais viável dentro de um programa que tem prazo, que tem que defender, que tem bolsa etc. etc.

\section{E que o deus Chronos não fique bravo.}

Que o deus Chronos... Essa questão também entra, entendeu? Então eu acho que é isso: o processo da tese passa pelo estudo, passa pelo estudo muito forte do orientando.

Mas em termos de autonomia e de tempo, há diferença entre o mestrado e o doutorado?

No mestrado não tem conversa. É fazer a dissertação com a consistência possível, mas sabendo que, como diz o Saviani, é uma monografia de base. Não é propriamente uma pesquisa de fundo.

Já que entraste nesse assunto, um ponto que tem sido pouco analisado quando se critica a diminuição 
do tempo é o fato de se ter um outro suporte tecnológico que dispensa viagens, por exemplo. Quando anteriormente você queria um documento, tinha de ir buscá-lo. A internet ou esses meios não têm sido "co-orientadores" ou suportes para facilitar e para encurtar o tempo?

Por exemplo, se você quer fazer um doutorado sanduíche no exterior, você entra no site das universidades de qualquer lugar do mundo e escolhe, fica sabendo onde estão as pessoas que te interessam, o que elas fazem, onde elas estão produzindo. Você manda um e-mail e, via de regra, as pessoas respondem, porque hoje há uma comunicação acadêmica interessantíssima. Vi isso agora com Robson e Sandra, que vão para a Inglaterra, se tudo der certo. Claro que eles são muito autônomos, são hiperantenados e sabem o que procurar, mas é espantosa a quantidade de pesquisadores com quem eles entraram em contato. Tiveram aceitação de muitos pesquisadores, inclusive do grupo do realismo crítico, que é um grupo até meio fechadão. Eles escreveram para o Lawson e ele os convidou para fazer seminário mensal em Cambridge!

\section{Linha direta.}

Linha direta e iniciativa deles. Claro que os estudos do realismo crítico foram minha iniciativa, como também a informação de que existe uma sociedade internacional do realismo crítico e de seus principais nomes. Mas os contatos foram por conta deles. Sem a internet, nada disso seria possível.

Mas o orientador tem que incentivar; e às vezes não tem que ensinar também?

Mas tem que ensinar, tem que ensinar. Aliás, eu diria que hoje uma condição para entrar numa pós-graduação deveria ser a familiaridade com uma língua estrangeira, de preferência o inglês, e com a internet.

\section{Mas ainda não é?}

Ainda não é, mas deveria ser. Porque eu não posso imaginar você escrever uma dissertação ou uma tese sem acesso mínimo às informações que um computador pode dar.

Mas nem sempre os recursos informacionais são considerados um meio de constrição do tempo, para ajudar a potencializá-lo.

É verdade. Quando eu imagino o que foi a elaboração da minha dissertação de mestrado e da minha tese de doutorado e o que é hoje, vejo um abismo tecnológico!

\section{Datilografando página por página...}

Datilografando página por página. Foi a secretária de meu ex-marido que datilografou a minha dissertação de mestrado. A tese de doutorado eu fiz sozinha no computador, no... Como é que chama mesmo... no XT. E, na hora de imprimir, naquela printerzinha, barulhenta, um aluno meu da economia ficou lá em casa três dias; dormia lá em casa, imprimindo dez páginas de cada vez. Aí tinha que acabar direitinho para continuar, porque não era o fim do capítulo, óbvio. Então ele tinha que organizar o texto, porque isso eu já não sabia fazer, para dar certinho, para dar continuidade na numeração das páginas seguintes. Faço um agradecimento especial a esse aluno, na tese, pois sem ele a impressão teria sido impossível.

A gente sabe que esses aparatos tecnológicos são legais, porque possibilitam um trabalho que na época da máquina de datilografar ficava muito mais difícil. Em contrapartida, se passa a ter acesso a um volume de informações muito maior do que anteriormente. Vês alguma implicação nisso ou não achas isso um problema?

Não, problema eu não acho. Acho que é uma questão, mais uma vez, de limites e disciplina. Porque se você entrar no Google e ficar enlouquecida, você não faz outra coisa na vida. Aliás, é um perigo. 
Houve um evento em Porto Alegre, da área de comunicação, cujo tema geral era: como lidar com o excesso?

Como lidar com o excesso. É uma boa questão. Você hoje tem uma quantidade imensa de informação que não é conhecimento. Creio que cabe às pessoas ter maturidade para delimitar o uso do tempo. Mas certamente cabe ao orientador ajudar nisso. Por exemplo, minhas bolsistas de IC estavam pesquisando a expressão "sociedade do conhecimento". Elas localizaram uma barbaridade de textos, mas pouquíssimas conceituações. Como se fosse um pressuposto. Ninguém discute, nem define. Isso é bárbaro, entendeu, isso nos permitiu a crítica ao uso indiscriminado da expressão que nos possibilitou apresentar, juntas, um paper em um congresso.

\section{Vocês fizeram um mapeamento?}

Exatamente, foi superlindo. Meninas de graduação fizeram um trabalho jóia. Claro, foi um trabalho muito bem delimitado e muito bem orientado, certo? Porque se você entrar no campo da informação primeiro que tem muito lixo - sem orientação, são grandes as chances de que se perca. Então eu acho que a questão da informação é fundamental para o conhecimento. Mas o acesso indiscriminado à informação pode atrapalhar.

Ao mesmo tempo em que o excesso é um problema, pode também ser um desafio à escolha e à autonomia. Com tantas informações, não dá para ficar em cima do muro...

Sem contar que, como orientador, tem o momento que você tem de colocar um limite, tem de interromper esse processo de busca. Quer dizer, se você está procurando "sociedade do conhecimento", aparecem 550 mil outras coisas, mas você tem que focalizar esse tema e ali ficar. Se não, não faz pesquisa.
Você teria alguma recomendação para os orientadores?

Quem sou eu para fazer recomendação para orientador? Além do mais, eu posso fazer recomendações que não são factíveis para a maioria dos orientadores... Mas que sejam pesquisadores, que se submetam aos critérios da comunidade científica, que orientem apenas as pessoas que estiverem no seu campo específico de pesquisa, que orientem poucas pessoas; isso que eu digo que é pouco factível, porque a universidade obriga você a orientar dez, doze, quinze... Então o que eu estou falando é o que nós aqui temos o privilégio de poder ainda. Mas isso é um privilégio desta universidade, nem outras federais têm. Então eu acho que são essas as indicações. E, é claro, tem de ter paixão. Sem o que não faz nada.

\section{Tem que gostar.}

Tem que gostar, tem que gostar de estudar. Para o pesquisador, o estudo é para a vida, é para sempre, entendeu? Não tem fim de semana, porque você está estudando sempre e, aliás, a hora que sobra para o estudo quase sempre é o fim de semana. Nós tivemos uma experiência desagradável porque o Ricardo, meu companheiro, quebrou o tornozelo em fevereiro e teve que ficar três meses de licença do trabalho e, desses três meses, ficou um mês engessado, depois um mês assim de muleta, enfim, nós praticamente não saíamos de casa porque era um sacrifício gigantesco. Nós nos demos conta de como fez pouca diferença para nossas vidas não sair de casa, porque na verdade a gente não sai mesmo. A gente estuda, a gente gosta de ler, a gente gosta do computador, gosta de conversar, de orientar, gosta de ficar ouvindo música, gosta de receber amigos; na limitação física, continuamos com a mesma rotina, entendeu? Então, de repente, a pesquisa também leva a um estilo de vida que é incompatível com outros, por exemplo, noitadas, festas... Com certeza não dá para você ir a uma festa, tomar um porre e ficar dois dias de ressaca, não dá tempo, não dá tempo. 
Maria Célia, queremos te agradecer o tempo que nos dispensaste. Muito obrigado.

Eu é que agradeço a oportunidade de ter conversado com vocês sobre essas importantes questões relacionadas à pós-graduação e a tudo que a envolve.

\section{Trabalhos de Maria Célia Marcondes de Moraes publicados recentemente}

. Paradigmas e adesões: temas para pensar a teoria e

a prática em educação. Perspectiva, ano 17, n. 32, p. 51-68, jul./ dez. 1999.

.Reformas de ensino, modernização administrada. A experiência de Francisco Campos: anos vinte e trinta. Florianópolis: UFSC/Centro de Ciências da Educação/Núcleo de Publicações, 2000.

Avaliação na pós-graduação brasileira: novos paradigmas, antigas controvérsias. In: BIANCHETTI, Lucídio; MACHADO, Ana Maria Netto. A bússola do escrever; desafios e estratégias na orientação de teses e dissertações. São Paulo: Cortez; Florianópolis: Editora da UFSC, 2002. p. 187-214.

. (Org.). O iluminismo às avessas. Produção de conhecimento e políticas de formação docente. Rio de Janeiro: DP\&A; Brasília: CNPq, 2003.
O processo de Bolonha vis a vis a globalização de um modelo de ensino superior. Perspectiva, Florianópolis, v. 24, n. 1, p. $187-204,2006$.

; DUAYER, M. História, estórias: morte do "real" ou derrota do pensamento? Perspectiva, v. 16, n. 31, p. 51-68, 1998.

; EVANGELISTA, Olinda; SHIROMA, Eneida. Política educacional. 4. ed. Rio de Janeiro: Lamparina, 2007. ; HORTA, José Silvério Baía. O sistema CAPES de avaliação da pós-graduação: da área de educação à grande área de ciências humanas. Revista Brasileira de Educação, n. 30, p. 95-116, set./dez. 2005.

; KUENZER, Acácia. Temas e tramas na pós-graduação em educação. Educação \& Sociedade, Campinas, v. 26, n. 93, p. 1.341-1.362, 2005.

; MÜLLER, R. G. A miséria da teoria: o debate de History workshop. Esboços, Florianópolis, n. 14, p. 25-36, jul./ dez. 2005.

; TORRIGLIA, Patrícia Laura. Educação light, que palpite infeliz. Indagações sobre as propostas do MEC para a formação de professores. Teias - Revista da Faculdade de Educação da UERJ, Rio de Janeiro, v. 1, n. 2, p. 51-59, jul./dez. 2000.

Recebido em abril de 2008 Aprovado em maio de 2008 